Laerte Idal Sznelwar ${ }^{1}$

Júlia Issy Abrahão ${ }^{2}$

Fausto Leopoldo Mascia ${ }^{1}$

\section{Trabalhar em centrais de atendimento: a busca de sentido em tarefas esvaziadas}

\section{Working at call centers and searching for meaning in "meaningless" tasks}

${ }^{1}$ Departamento de Engenharia de Produção da Escola Politécnica da Universidade de São Paulo, Brasil.

${ }^{2}$ Instituto de Psicologia da Universidade de Brasília, DF, Brasil.

\begin{abstract}
Resumo
Este artigo apresenta uma discussão relativa a aspectos significativos do trabalho em centrais de atendimento estudadas sob o ponto de vista da ergonomia e da psicodinâmica do trabalho. A discussão se apóia nos estudos realizados em empresas situadas nas cidades de São Paulo e Brasília entre meados dos anos 1990 e início dos anos 2000. As centrais de atendimento em questão se dedicam sobretudo a atividades financeiras (cartões de crédito, bancos), serviço público e telefonia (celular e fixa). Os resultados apontam para a importância de se modificar os paradigmas que norteiam o projeto do trabalho dos atendentes visando reverter os processos de sofrimento e adoecimento no trabalho. Além disso, eles sugerem novos paradigmas nos quais o trabalho é considerado como uma ferramenta de desenvolvimento profissional. Portanto, um meio para a realização pessoal dos atendentes e também para atingir objetivos de produtividade e qualidade compatíveis com o desenvolvimento humano e das organizações.
\end{abstract}

Palavras-chaves: saúde do trabalhador, paradigmas organizacionais, sofrimento no trabalho.

\begin{abstract}
Based on ergonomics and psychodynamics of work, this article discusses some significant aspects of work at call centres. The results are based on research carried out in companies located in São Paulo and Brasília, between the 90s and the beginnings of the year 2000. The call centers under study are mainly in the area of finance (credit cards and banks), but they are also from public services and telephone companies. Other than showing the importance of changing paradigms that guide operators' work, in order to reduce suffering and illness, the results suggest new paradigms in which work is a tool for operators' professional growth. Therefore, work as a mean to personal fulfilment, as well as to achieve productivity and quality goals, respecting human development in organizations.
\end{abstract}

Keywords: workers' health, organizational paradigms, suffering at work. 


\section{Introdução}

Neste artigo, pretende-se analisar dimensões relativas ao trabalhar em centrais de atendimento identificando as dificuldades que os atendentes enfrentam para responder às exigências da produção em situações nas quais as tarefas foram concebidas a partir de paradigmas sustentados por princípios simplificadores da realidade da produção de serviços e do trabalho humano.

Esta discussão é fruto de aproximadamente uma dezena de estudos desenvolvidos por duas equipes de pesquisa: do Departamento de Engenharia de Produção da Escola Politécnica da Universidade de São Paulo e do Núcleo de Ergonomia Cognitiva e Saúde do Instituto de Psicologia da Universidade de Brasília. Esses estudos foram desenvolvidos em centrais de atendimento ligadas ou contratadas por diferentes tipos de empresa: bancos, empresas de cartão de crédito, empresas de telecomunicação, serviço público. Os estudos foram desenvolvidos nas cidades de São Paulo e de Brasília.

As demandas para o desenvolvimento desses estudos estavam associadas a problemas de saúde, em sua maioria Distúrbios Osteomusculares Relacionados ao Trabalho (DORT), conhecidos também como Lesões por Esforços Repetitivos (LER). Ressalte-se que, em quase todas as situações estudadas, o objetivo principal das empresas era o de reduzir os problemas de saúde crescentes nas centrais de atendimento sem que houvesse, de fato, a intenção de transformar profundamente os processos de produção e o conteúdo das tarefas. Havia, sim, uma disposição para tratar de aspectos parciais da questão, como o mobiliário e o sistema de pausas.

Os métodos empregados nesses estudos permitiram um diagnóstico aprofundado das questões ligadas ao trabalhar e a suas conseqüências para a saúde dos trabalhadores, para o seu desempenho e para o seu desenvolvimento profissional. Esses resultados trazem à tona um debate interessante relativo às intenções dos atores sociais na empresa com relação à efetividade das mudanças. Eles apontam ainda problemas significativos ligados ao projeto do trabalho, o que poderia ser reapropriado na perspectiva de um projeto de reformulação profunda do conteúdo das tarefas e da organização do trabalho. Mas, de fato, malgrado o quadro alarmante de adoecimento, na maioria das centrais estudadas, tanto na modalidade de atendimento passivo quanto no ativo, o modelo da organização do trabalho se manteve vinculado aos princípios propostos por Taylor no século passado. Portanto, a questão chave que norteou as pesquisas e a proposta deste artigo é: em que medida esses princípios de organização do trabalho contribuem para o quadro de adoecimento comum a essas empresas?

Os métodos de análise adotados nesses estudos se inspiram na Análise Ergonômica do Trabalho - AET (GUÉRIN et al. 2001) e na Ação em Psicodinâmica do Trabalho - APT (DEJOURS, 2004). No caso da AET, buscou-se levantar dados relativos à tarefa e seus determinantes. Para tanto, foram realizadas entrevistas com gestores, supervisores diretos, projetistas dos sistemas de produção, responsáveis pela gestão e implementação de sistemas de informação, responsáveis pelos sistemas de qualidade e também com profissionais da área de propaganda e venda. Além das entrevistas, buscaram-se dados secundários relativos a procedimentos operacionais, scripts, manuais de qualidade e dados de produção. Também se levantaram dados demográficos, incluindo idade, sexo, escolaridade, senioridade, e dados epidemiológicos obtidos junto aos serviços de saúde das empresas. Em três delas realizou-se um levantamento junto aos trabalhadores visando identificar sintomas de desconforto ou dor vivenciados por eles. Cada estudo teve suas peculiaridades principalmente no que diz respeito à disponibilidade dos dados existentes nas empresas. Entretanto, em todas elas foi possível obter informações bastante significativas que propiciaram a construção dos problemas identificados nas tarefas e que puderam nortear as observações e as análises das atividades. A partir da análise das tarefas que propiciaram a construção das primeiras hipóteses relativas à gênese dos problemas de saúde, foram realizadas observações abertas e sistemáticas da atividade de trabalho. Uma outra questão metodológica importante foi o envolvimento dos trabalhadores. Em todas as situações, houve acompanhamento de trabalhadores e, em parte dos estudos, foram criados grupos com trabalhadores voluntários nos quais se discutiram questões ligadas ao seu trabalho para relevar as ações por eles empreendidas. Eles se envolveram em proces- 
sos de validação dos resultados e na construção das propostas de melhorias.

No caso da APT, trabalhou-se com grupos de expressão (DEJOURS, 2004) com o objetivo de criar um espaço de discussão para favorecer a troca de experiência entre os trabalhadores participantes. Nesse percurso, buscou-se a construção de um sentido comum sobre o trabalhar e a re-apropriação por parte de cada membro do grupo da sua história e da sua experiência, muitas vezes dolorosa e com seqüelas. Para a constituição desses grupos, fato que ocorreu em três empresas, propôs-se aos trabalhadores, numa palestra inicial, da qual participaram todos os integrantes das centrais de atendimento, a possibilidade de constituir grupos de voluntários para o desenvolvimento da proposta de ação. Esses grupos se reuniram regularmente (a cada sete ou quinze dias), totalizando entre 18 e 24 horas de reuniões. Ao final, um documento foi discutido e validado com os participantes antes de ser entregue à empresa e aos participantes para que pudessem receber o resultado do trabalho desses coletivos de expressão.

Assim, os estudos nos quais este artigo se apóia foram formulados tanto a partir de uma abordagem de natureza quantitativa quanto qualitativa. Essa opção se deve, sobretudo, à possibilidade de qualificar os dados de natureza quantitativa, explicitando dimensões subjetivas do trabalho para as quais a abordagem quantitativa se mostra lacunar.

Não é o propósito deste artigo detalhar cada estudo e os resultados obtidos. O que se pretende é uma reflexão consubstanciada apoiada nesses resultados. Assim, a estrutura foi delineada a partir da compreensão das situações analisadas e que podem contribuir nas reflexões dos projetos e no gerenciamento diferenciado das situações de trabalho em centrais de atendimento.

Malgrado a diversidade geográfica e as situações de trabalho que subsidiaram este artigo, além da defasagem de tempo entre os estudos, a articulação dos diferentes resultados só foi possível devido à constatação de que, embora a tecnologia tenha passado por mudanças significativas, a organização do trabalho e o conteúdo das tarefas pouco evoluíram.

Nessa perspectiva, o artigo inicia uma discussão acerca dos paradoxos sob os quais se assenta a concepção do trabalho nas centrais de atendimento. Em um primeiro momento, analisa algumas incompa- tibilidades entre as prescrições e a realidade. Apresentam-se então, as características das prescrições, cotejando a sua compatibilidade com a natureza da atividade de atendimento. Em seguida, apresenta-se o ponto de vista dos atendentes em relação ao controle, como eles são escutados, como são monitorados por meio de sistemas eletrônicos. Nesse caso, seria pertinente indagar se as formas de controle usuais nas centrais de atendimento são compatíveis com as necessidades de assegurar, ao mesmo tempo, o nível de produção e de qualidade dos serviços e o bem-estar dos trabalhadores.

\section{Paradoxos de uma tarefa esvaziada}

Trata-se, sobretudo, dos casos em que as tarefas dos atendentes são definidas por um grande número de normas, procedimentos, atitudes e responsabilidades prescritas, que deveriam ser seguidas à risca. Ressalte-se que muitas normas são importantes e são, na maioria das vezes, respeitadas, pois ajudam a garantir a segurança da operação. Outras são restritivas, pouco compreendidas, podendo ser caracterizadas como normas de conduta pouco adequadas pela ausência de margem de manobra. Isso é mais comum nas centrais baseadas em conceitos de serviços de massa.

Os cenários criados para se trabalhar tendem a levar os atendentes a uma situação de impasse. A maneira como são concebidas as tarefas pode criar injunções paradoxais. Ao mesmo tempo em que é solicitada a iniciativa dos atendentes, não há espaço para sua manifestação. Ao mesmo tempo em que se exige um não envolvimento com o cliente, é necessário ouvi-lo, compreendê-lo e resolver o seu problema ou, ainda, conquistá-lo, seduzi-lo para que ele adquira um produto ou serviço. Piores são as situações nas quais o atendente não pode resolver o problema do cliente, embora saiba como fazê-lo; essa situação se configura como típica de impedimento para agir (SZNELWAR, 2003).

$\mathrm{O}$ atendente necessita ser rápido e manter a atenção constante, pois deve atender as ligações o mais rapidamente possível. Em algumas situações não há tempo nem para terminar uma ligação e já há outro cliente na linha. Deve se abster de quaisquer réplicas pessoais, ser imparcial às criticas e argumentos dos clientes, não tecer comentários ou julgamentos. Deve utilizar expressões pré-definidas, mantendo o tom de voz apropriado à situação. É necessário se manter cordial e calmo, guardar o equi- 
líbrio emocional mesmo em situações adversas, como naquelas em que é ofendido e quando há um comportamento agressivo de clientes. Espera-se que tenha habilidade para contornar situações difíceis e inusitadas.

Deve também demonstrar um genuíno interesse nas demandas dos clientes, procurando entender e atender às suas solicitações. Deve gerenciar o atendimento de modo que a ligação não seja longa e ao mesmo tempo não deve apressar sua conclusão. $\mathrm{O}$ atendente precisa transmitir segurança e confiança frente à diversidade de demandas dos clientes sem mostrar hesitação ou indecisão. Deve ter uma boa capacidade de argumentação e convencimento, além de conhecer todos os produtos e serviços oferecidos. Precisa ter agilidade na busca das informações nos sistemas disponibilizados pela central. Deve se dirigir ao cliente de forma espontânea e natural, porém, para dialogar, precisa seguir um texto preconcebido. $\mathrm{O}$ atendente precisa ser cordial e simpático sem expressar sentimentos e emoções. E, por último, deve estar atento a qualquer palavra ou frase proferida, mantendo uma constante vigilância para se adequar às prescrições.

É difícil acreditar que algum ser humano possa se enquadrar na situação descrita acima. No entanto, ela é verdadeira e atualmente emprega centenas de milhares de trabalhadores, que devem "funcionar" nesse tipo de contexto e responder aos requisitos citados. Portanto, trabalhar, ou melhor, laborar, no sentido proposto por Arendt (1981), seria a regra do jogo. A obra pessoal, o ergon, estaria fora de cogitação. A despersonalização do agir no trabalho, a imaterialidade, a intangibilidade, o individualismo são pilares desta lógica que levaria ao sofrimento patológico, no sentido proposto por Dejours (2001), sofrimento que se torna "visível" no sistema musculoesquelético, na pele, no sistema digestivo, entre outros, ou ainda expresso como "malestar" psíquico (DEJOURS, 2000).

Coerente com essa visão de mundo mecanicista e funcionalista (MAGGI, 2006), os atendentes são considerados pelas empresas apenas receptores de chamadas, sem possibilidade de agir além daquilo que lhes foi prescrito. Qualquer transformação no processo de trabalho ou mudança nos procedimentos deve ser fortemente combatida. Reduz-se essa situação a uma atividade de interação entre o atendente e o cliente, ao contrário de tomar partido da heteroge- neidade, privilegiando a diversidade, considerando os contextos do sistema de uso e de produção. Nessa perspectiva, as centrais de atendimento conseguem criar uma combinação inédita de modalidades externas e internas de produção de disciplina (ABRAHÃO \& SANTOS, 2004).

As conseqüências do cerceamento às possibilidades do agir podem se expressar em problemas de saúde e no desempenho dos trabalhadores. A iniciativa e a criatividade são cerceadas pela maneira como é organizado e controlado o trabalho. A pessoa impedida tem que fazer pouco, movimentar-se pouco e inclusive evitar ser ela mesma. Essa afirmativa parece um paradoxo, uma vez que este tipo de trabalho exige muito ritmo, muita atenção, muito uso da memória, muita imobilização postural, isto é, exige muito de pouco, de características e propriedades muito específicas do ser humano (SZNELWAR, 2003).

\section{Relação de serviço e reificação}

Dentre as conseqüências da adoção desse tipo de modelo, pode-se identificar uma certa desumanização das relações de serviço, visto que o trabalho do atendente deve ser o mais próximo possível de algo, de um objeto passível de reprodução e de controle. É contraditório que uma relação intersubjetiva, base de uma atividade em que o relacionamento com o cliente é chave, seja transformada em "coisa”, num processo de reificação.

Essa questão remete, como ressalta Dejours (1987), aos estudos sobre as telefonistas realizados por Le Guillant, em que o autor afirma que este profissional deve reprimir suas iniciativas, enquadrar sua linguagem, não apresentar qualquer expressão de cansaço, não se irritar, não expressar descontentamento ou ainda prazer diante de uma situação de atendimento. A sua afetividade deve ser proscrita. Por outro lado, como devem ser simpáticos, a sua afetividade é prescrita.

Wisner (1994), ao comentar o mesmo estudo de Le Guillant sobre a neurose das telefonistas, aponta a contradição entre a tarefa muito rígida imposta às telefonistas e as dificuldades que se manifestam no momento do atendimento. A relação de serviço criada é dificultada, pois o diálogo com o cliente não é favorecido. O cliente precisa entender a racionalidade da empresa, enquadrar-se naquilo que é previsto, expressar-se usando uma linguagem compatível com a da empresa. Ele também tem 
um comportamento prescrito que deve estar enquadrado, precisa ser educado para receber o serviço. Interessante notar que, em princípio, numa relação como esta, o cliente deveria ser considerado como coprodutor do serviço.

Ainda na perspectiva da relação com o cliente, ponto chave de encontro de serviço, os atendentes não podem dar vazão as suas emoções para demonstrar alegria, solidariedade, raiva, tristeza ou decepção. Às vezes, ao desligar uma ligação ou ao colocar o cliente em situação de espera, os atendentes buscam extravasar seus sentimentos por meio de gritos, xingamentos. Isso acontece, principalmente, porque não está previsto um acompanhamento de fato do problema do cliente e, quando há conflito, este evolui rapidamente para situações de impasse. Não é à toa que os atendentes abusam do uso de verbos no gerúndio ao se comunicar com os clientes. Eles percebem que, em muitas situações, respostas mais precisas não são possíveis. Eles não têm certeza se o problema será encaminhado ou ainda se, em tempo real, caso o atendente não tenha como responder adequadamente à demanda do cliente, o risco de se criar impasses aumentará. Segundo eles, esse tipo de situação aumenta sua ansiedade e sofrimento.

A importação de paradigmas do taylorismo e do fordismo, em nome da racionalização da produção, pode constituir a grande fonte dos problemas citados. Esse tipo de produção “em massa” de serviços seria uma repetição de certos erros do passado? Ou seria ainda pior: uma espécie de farsa, pois a prestação de serviços constitui uma relação entre sujeitos e a sua despersonalização se torna uma das causas fundamentais de sofrimento para os trabalhadores? A busca frenética por produtividade, a luta constante contra os "tempos mortos" teriam como fruto uma compressão progressiva dos tempos e uma conseqüente "contração dos corpos". Alguns resultados obtidos nesses estudos mostram uma correlação entre a redução de tempos médios de atendimento (TMA) e o aumento significativo de afastamentos por LER/DORT (MASCIA \& SZNELWAR 1998; SZNELWAR et al.,1999).

Além dos problemas de natureza física, encontraram-se indícios significativos de problemas de ordem psíquica, sendo que, à época, não havia dados epidemiológicos capazes de confirmá-los. Entretanto, os relatos de atendentes e de outros trabalhado- res nas empresas apontavam para uma incidência significativa de sofrimentos moral e psíquico.

Nesse tipo de tarefa, não haveria praticamente espaço para desenvolver um "agir expressivo" mais harmonioso. Segundo Dejours (2001), o agir expressivo seria o modo como o corpo se mobiliza a serviço da significação, a serviço do ato de significar a outrem o que vive o "eu". O corpo é mobilizado como um todo. As funções orgânicas são mobilizadas em proveito da encenação do sentido. O agir expressivo constitui a recapitulação, em uma única noção, do enunciado e da sua dramaturgia. Negligenciar a exigência da dramaturgia é construir um discurso monocórdio, achatado, inexpressivo, que pode levar a uma incompreensão por outrem e se tornar fonte de sofrimento patogênico.

A atividade dos atendentes é basicamente de relação, logo, ela deveria ser uma âncora fundamental para o desenvolvimento das ações. A prescrição atinge diretamente aspectos do comportamento considerado como aceitável e produtivo com relação ao desempenho do setor. Questiona-se até que ponto isso pode ser prescrito e se seria produtivo fazê-lo. Há uma diferença significativa entre a adoção de condutas cordiais, em que haveria espaço para que o atendente efetivamente pudesse responder às demandas dos clientes, fato que pode $\mathrm{e}$ deve ser favorecido e estimulado pelas empresas, e um comportamento estereotipado, restrito a ações padronizadas, no qual a possibilidade de desenvolver estratégias para resolver problemas e para acompanhar o processo de atendimento ao cliente de uma maneira mais efetiva não é prevista, sendo mesmo combatida, proibida.

\section{Um sistema de produção coerente com seus princípios?}

As diferentes racionalidades que orientam o projeto da produção e das tarefas, assim como a gestão da produção e do trabalho, nas centrais de atendimento nem sempre são coerentes entre si. Muitas vezes, aqueles que prescrevem não estão em sintonia com a atividade, que por sua vez pode ser incompatível com a demanda colocada pelo cliente, com as regras de funcionamento ou, ainda, com os critérios de avaliação. Ao se ater apenas ao que diz respeito à racionalidade técnica, encontraram-se, entre os diferentes estudos que dão sustentação a este artigo, dissonâncias significativas entre as áreas de produção do 
atendimento ao cliente, especificamente as centrais de atendimento, e outros setores, como vendas, marketing, crédito. Ações empreendidas em outros setores tinham impacto significativo na linha de frente (central de atendimento) sem que houvesse um concerto anterior e uma preparação das operações. Ao dirigir a questão para a interface entre o cliente e o atendente, identificaram-se conflitos que aí se construíam, pois, em muitas situações, o cliente não aceitava e não entendia aquilo que a empresa definia como possível e como passível de ser solucionado ou encaminhado. Nesse caso, muitas vezes, os próprios

\section{0 prescrito e o que se passa...}

Os resultados desses estudos mostram que existe uma distância entre o que é prescrito pela empresa e a realidade do cotidiano. No desenvolvimento de ações em ergonomia, é necessário atuar na dialética entre o trabalho prescrito e o trabalho real. Nesse sentido, considera-se que atividade de trabalho é uma forma de resposta à definição da tarefa, objeto da prescrição. As dificuldades encontradas no desenvolvimento do trabalho, muitas vezes, decorrem do fato da tarefa ser definida sem que se considere a variabilidade intrínseca que permeia toda a situação de trabalho.

Assim, para trabalhar bem, o atendente se vê obrigado a elaborar estratégias operatórias para responder às exigências contidas na definição da tarefa. Essa possibilidade pode ser muito favorável à realização pessoal e profissional desses trabalhadores, pois este seria um espaço para o desenvolvimento de estratégias criativas, de soluções interessantes, de consolidação do coletivo de trabalho.

Entretanto, na maioria das centrais estudadas, a organização é rígida, não há margem de manobra para modificações no atendimento e o que se observa nas relações com os colegas e a hierarquia é um bloqueio. Trabalhar sob essas condições tem conseqüências tanto na qualidade da prestação do serviço quanto na saúde mental dos trabalhadores. Uma série de instruções com relação à tonalidade da voz, linguagem, tratamento ao cliente, cadência do diálogo, ações e expressões a serem evitadas pelos atendentes são descritas por Sznelwar e Mascia (1998). Os autores constataram que as instruções se referem operadores não concordavam, ora com a empresa, ora com os clientes.

A busca por ações mais equilibradas, pelas quais fosse possível acompanhar o caso de clientes que tinham problemas a serem solucionados, não era permitida. Qualquer ação que divergisse do responder, em tempo real, ao cliente deveria ser enviada para setores de retaguarda e o atendente não era informado do encaminhamento dado ao problema. Posteriormente, ao ser confrontado novamente com o mesmo cliente, ficava perdido e, se não soubesse responder, o cliente se mostrava ainda mais nervoso e irritado.

somente às situações conhecidas ou previstas, portanto, não comportam a diversidade de ocorrências com que os atendentes se deparam no cotidiano de atendimento.

Como estratégias possíveis que podem significar certa resistência ou mesmo a busca para facilitar o trabalho, pode-se citar que muitos atendentes, de forma explícita ou longe dos olhos da supervisão, possuem um bloco de notas onde registram as informações sucintas sobre algum produto ou serviço novo e fotocópias dos scripts mais difíceis de se localizar no programa de computador. Em princípio, de acordo com o previsto pelas empresas, tudo deveria constar no sistema e os atendentes não deveriam utilizar outras ferramentas de trabalho, como lápis e papel. Esse posicionamento é um reflexo de certa prepotência da prescrição apoiada em pressupostos de infalibilidade do sistema e da possibilidade de contemplar todas as situações. Apesar de ser considerada como uma atividade simples pelos responsáveis pelas prescrições, espera-se que os atendentes tenham uma memória com capacidade de armazenamento ilimitada e que possa ser acessada rapidamente e em tempo real. Da maneira como foi concebido o trabalho, não há espaço para o reconhecimento do papel mediador do atendente. Então, o excesso de prescrição pode dificultar o alcance dos resultados esperados, pois dificulta a gestão por parte dos atendentes devido à diversidade de ligações e à variabilidade de usuários.

Confrontado com essa situação, não resta ao operador outra saída senão elaborar estratégias operatórias para tentar 
minimizar as dificuldades encontradas na execução das tarefas, procurando manter os patamares de qualidade e de produtividade e sem comprometer o equilíbrio da situação (GUBERT, 2001). Entretanto, um código rígido de conduta limita a elaboração de respostas criativas dos operadores (ABRAHÃO \& TORRES, 2004). As autoras demonstram que o sucesso do trabalho, nesses casos, assenta-se na transgressão, pois o modelo de organização do trabalho não permite a flexibilidade necessária para lidar com situações variadas e complexas. Nem todas as situações fazem parte da prescrição, então, os atendentes desenvolvem estratégias para responder de maneira apropriada e manter a atividade em um nível satisfatório para eles e para a central de atendimento. Para efetivamente atender ao cliente, decodificar o script para tornar compreensível a sua resposta à demanda do cliente, o atendente se vê obrigado a transgredir (ABRAHÃO \& TORRES, 2004).

Essas transgressões ou ações que possibilitam um desempenho mais adequado e, quiçá, com menos sofrimento ficam escondidas, camufladas, condenadas aos "porões" da empresa, uma vez que elas não podem ser reconhecidas oficialmente. Atesta-se a impossibilidade de ter reconhecido o esforço criativo e a elaboração de um julgamento da utilidade (DEJOURS, 2003) dessas ações fica prejudicada. Quando descobertas ou não acobertadas pelos supervisores, podem servir de substância para punições.

Esses exemplos reforçam a dinâmica do atendimento, que se caracteriza pela variabilidade de solicitações e pelo número elevado de situações que exigem constantemente do atendente vigilância relacionada ao processo de busca de informações, ao tratamento contínuo das solicitações para resolver com rapidez as demandas do cliente e a uma adequada utilização do sistema. Vilela e Assunção (2004) descrevem esse tipo de trabalho como basicamente de tratamento de informações nem sempre disponíveis e, muitas vezes, de difícil interpretação. As dificuldades ligadas às restrições impostas pelas prescrições seriam ainda maiores, pois há uma série de atitudes que poderiam resolver os problemas dos clientes, no entanto, os atendentes não podem agir nesse sentido.

Em síntese, ao se cotejar a descrição do trabalho pela organização com a atividade real dos atendentes, pode-se afirmar que estas duas racionalidades não são compatíveis e que existe uma distância expressiva entre o prescrito e o real. Essa discrepância reflete na atividade dos atendentes de forma significativa, aumentando a carga de trabalho nas dimensões cognitiva e psíquica. Estes resultados vão ao encontro dos de Abrahão e Torres (2004), nos quais elas descrevem diferentes estratégias operatórias elaboradas pelos atendentes como forma de atender às demandas dos usuários.

Os estudos desenvolvidos têm mostrado uma organização pouco ou nada flexível: flexíveis são os trabalhadores. O tipo de organização do trabalho encontrado nos estudos em questão está em contradição com aquele proposto por Gilbert de Terssac e Bruno Maggi (2004). Esses autores afirmam que a organização do trabalho, assim como sua prescrição, deve ser flexível, pois problemas são causados quando se busca simplificar uma tarefa sem considerar a realidade. Nesta perspectiva, sugere-se que a formalização da prescrição seja limitada, permitindo possíveis renegociações e ajustes das regras e das decisões como forma de compatibilizar a prescrição com a natureza da atividade de atendimento.

\section{Os procedimentos: um guia ou uma camisa de força?}

A inadequação entre o script e a natureza da atividade de atendimento é reforçada pelo fato dos operadores atenderem a uma variabilidade muito grande de clientes, conseqüentemente uma alta demanda de processamento de informações. Eles têm que entender e decodificar adequadamente a demanda seguindo as racionalidades dos clientes e responder na racionalidade da organização (por vezes divergentes, senão contraditória, se forem considerados os pontos de vista dos diversos setores e mesmo as diferenças no modo de agir das chefias), muitas vezes sob pressão temporal, pois o cliente quer uma resposta imediata. Além disso, nem sempre o cliente tem clareza do que quer e o atendente é confrontado com procedimentos rígidos, não podendo se desviar das prescrições impostas pela organização. A adoção rígida do script é, portanto, problemática para o desempenho do atendente e o sucesso da interação. Os operadores verbalizam a sensação de que, por vezes, soam falsas todas 
estas formalidades no decorrer do diálogo, e mesmo assim eles devem segui-las.

Depreende-se dos resultados obtidos nessas análises da atividade que as características dos scripts não são compatíveis com a realidade de atendimento, pois, para dar conta das demandas dos clientes, o atendente é obrigado a construir constantes adaptações. Para tal, ele busca conciliar aquilo que pode ser feito com aquilo que seria necessário para resolver os problemas. Nesta perspectiva, a atividade caracteriza-se por uma dinâmica de regulação permanente do trabalhador para manter o equilíbrio e obter os resultados esperados dentro das condições possíveis. "Aquilo que a coisa pede (realidade) é diferente daquilo que é pedido (prescrição - tarefa)" (GUERIN et al., 2001). Aí se situa um ponto bastante delicado desse tipo de trabalho, pois se abre espaço para mal-entendidos, punições, avaliações negativas, em suma, pode ser um fator agravante para o sofrimento dos trabalhadores, pois a sua iniciativa não é reconhecida, não se torna parte de um conhecimento coletivo, fundamental para o desenvolvimento do gênero e do estilo profissional (CLOT, 1999).

A construção dos scripts é baseada em pressupostos segundo os quais o cliente teria um raciocínio linear e previsível. Assim, as possibilidades previstas não agregariam nem deixariam um espaço que permitisse articular as possíveis variáveis da situação de atendimento. As principais queixas dos atendentes estão ligadas à rigidez, pois o diálogo não pode fluir e adquire características rígidas, torna-se robotizado e mecanizado, dificultando a construção de sentido no trabalho (CALDERON, 2005). A maioria dos atendentes, apesar destas queixas, não deseja a eliminação do script e sim a sua flexibilização (ZIMMERMAN, 2005). Eles querem que ele sirva como um roteiro, como um orientador do atendimento. Essas questões são semelhantes às encontradas por Gubert (2001): uma parte dos operadores vê o script como um componente negativo do controle, enquanto outros apontam aspectos positivos, citando-o como um orientador e auxiliar para o atendimento.

A situação de atendimento é cheia de imprevistos, de situações problemáticas, o que requer do trabalhador habilidades, experiência para prever, equacionar e decidir para fazer frente a esses imprevistos (SATO, 2002). E eles acontecem mesmo naqueles processos considerados simples e repetitivos, como se diz freqüentemente da atividade das centrais de atendimento. Em muitas situações, os trabalhadores se sentem “impedidos”, pois não podem agir, não podem responder, não podem resolver. Em outras situações, para se defenderem da ira dos clientes, fazem-se passar por "máquinas", respondendo como se fossem uma gravação, que se revela como uma estratégia para evitar problemas.

Há questões significativas quanto à variabilidade relacionada à idade, sexo, grau de instrução, estado civil e estado de origem dos clientes. Eles utilizam linguagens distintas na comunicação. Os atendentes precisam adequar a sua linguagem e também compreender as dos clientes.

Nestes cenários, cheios de variações, dinâmico, mutante, é que a atividade se desenvolve. É por meio desses cenários que se pode apreender diferenças significativas com relação àquelas previstas nos projetos (ABRAHÃO, 2000). O que se observa no dia-a-dia é que a estabilidade dos manuais e normas não corresponde ao real, pois no trabalho ocorrem variações contínuas.

\section{A ficção do controlar}

De maneira coerente com a proposta de organização do trabalho baseada em paradigmas tayloristas, o trabalho dos atendentes é controlado para garantir que sejam respeitados os procedimentos da tarefa. Esse tipo de controle se dá por meio de sistemas de escuta e também de acompanhamento a partir do terminal da supervisão, para que os supervisores avaliem em tempo real o que se passa no atendimento. Além desse tipo de controle de conteúdo, há também um controle feito a partir de sistemas informatizados que servem para monitorar os diferentes tempos (tempo de ligação, tempo de conexão, número de ligações, filas, entre outros).

Portanto, haveria dois tipos principais de controle que fazem parte desse universo: um eletrônico, que permite um acompanhamento, em tempo real, dos tempos de atendimento, das filas, do tempo em que o atendente está conectado ao sistema, das pausas, podendo ser usado para controle da produção de uma central e, também, ser usado para um estrito controle do atendente; o outro é aquele feito pela hierarquia (supervisão e gerência), que permite, em tempo real, que estes façam uma escuta e mesmo um acompanhamento das ações do atendente no sistema (aonde navega, as informações que ele introduz, por exemplo). Vale lembrar ainda que as ligações podem 
ser gravadas e o são em certos tipos de atendimento, principalmente quando há o risco de haver erros que levem a perdas e a conflitos posteriores entre os clientes e as empresas.

O monitoramento do conteúdo, feito pelos supervisores, visa controlar a suposta utilização correta dos procedimentos (VILELA \& ASSUNÇÃO, 2004). Segundo o ponto de vista defendido pelas gerências das empresas estudadas, esse procedimento é uma tentativa de homogeneizar o atendimento em situações cuja natureza não é homogênea. Isso impõe aos atendentes o uso de várias habilidades, como a rapidez de raciocínio e a flexibilidade para procurar seguir o prescrito e ao mesmo tempo atender de maneira adequada os clientes. Ressalte-se que, em muitas situações, há contradição entre a racionalidade técnica e a racionalidade do cliente. Os atendentes se encontram, então, em uma situação paradoxal e, mesmo sabendo que o cliente tem razão, ele é obrigado a seguir o determinado pela empresa. Como viver essas situações sem se sentir frustrado, sem apresentar sinais de depressão, de cansaço e mesmo de esgotamento?

Estudo conduzido por Gubert (2001) reforça o fato de que o monitoramento sistemático aumenta os constrangimentos aos atendentes, pois não podem suprimir algumas falas prescritas ou conduzir o diálogo de forma mais personalizada segundo as características e necessidades do cliente.

Os atendentes, pelo fato de estarem submetidos ao monitoramento, são obrigados a seguir um conjunto de condutas bastante padronizado e controlado. Essa padronização é rígida na maneira de falar, no que dizer, no que não dizer, na forma de conduzir um diálogo (SZNELWAR \& MASCIA, 1997).

Esses estudos demonstram que os atendentes, ao seguirem rigorosamente o script, muitas vezes não conseguem construir um diálogo verdadeiro, não conseguem entender e se fazer entender pelo cliente. Devido a este controle rigoroso, eles se sentem impedidos de usar a criatividade para construir um diálogo mais espontâneo e natural. Entretanto, alguns atendentes, mesmo correndo o risco de serem penalizados na sua avaliação, direcionam os scripts para se adequarem ao perfil do cliente (TORRES, 2001).

Os estudos realizados em centrais de atendimento mostram que o controle é ora visível, ora invisível, mas paira como constante, como permanente. Será que todos eles são pertinentes para assegurar a eficiência e a eficácia no trabalho?

A falsa idéia de tudo controlar e garantir, portanto, o bom andamento das operações resulta nesse tipo de monitoramento do trabalho graças à tecnologia hoje disponível e quiçá pela falta de um debate mais profundo com relação aos limites éticos das possibilidades de controlar as pessoas.

Há também outros tipos de controle, como aquele em que os atendentes recebem ligações com o propósito de avaliálos. É interessante que, nesses casos, eles relatam que o "cliente" conduz a ligação segundo o procedimento, diferentemente do que ocorre em situações reais, portanto percebem facilmente que se trata de uma situação "falsa", pois nenhum cliente constrói um diálogo "no procedimento".

Através de toda esta sistemática de controle, sobretudo porque as ferramentas informatizadas permitem exercer um controle muito mais constante, há um reforço à idéia de que este possa ser completo, total. Esta idéia, oriunda de pontos de vista totalitários, poderia ser comparada com algumas questões já levantadas por Foucault (1987). Haveria, portanto, uma certa analogia com as críticas desenvolvidas por esse autor:

Trata-se de um controle intenso, contínuo; ocorre ao longo de todo o processo de trabalho; não se efetua - ou não só - sobre a produção (natureza, quantidade de matérias primas, tipos de instrumentos utilizados, dimensões e qualidade dos produtos) mas leva em conta a atividade dos homens, seu conhecimento técnico, a maneira de fazê-lo, sua rapidez, seu zelo, seu comportamento.

A monitoração acaba sendo, na maioria das centrais, uma via de mão única e, segundo os atendentes, elas se tornam avaliações onipotentes, que além de gerar atitudes antipáticas causam insegurança e sentimento de injustiça, pois funcionam como uma imposição na qual não existe espaço para a confrontação de pontos de vista divergentes para a negociação.

O excesso de controle dificulta a realização do trabalho e gera nos atendentes um sentimento de impotência que se manifesta no paradoxo de que, para bem atender, é preciso transgredir (ABRAHÃO \& TORRES, 2004). Ou ainda, segundo Sznelwar et al. (1999), que, aliado ao conteúdo inade- 
quado do trabalho, o excesso de controle, favorecido e facilitado cada vez mais pelas tecnologias informatizadas, ao permitir o acompanhamento das atividades em tempo real é uma possível fonte geradora de sofrimento psíquico.

Em algumas das centrais, o controle é também realizado por meio de câmeras espalhadas de maneira estratégica para monitorar o ambiente de operações. Estas imagens são armazenadas para eventuais consultas. A exposição contínua a olhares invisíveis reforça nos atendentes o sentimento de falta de confiança por parte da organização.

Os relatos de estudos indicam que os atendentes admitem até a possibilidade da monitoração funcionar como um instrumento positivo, como uma fonte de aprendizado, aprimoramento, correção das falhas e melhoria do atendimento. No entanto, eles ressaltam que o instrumento não deveria ser utilizado como um mecanismo punitivo. Isso reforça a idéia de que os sistemas de ajuda para o processo de aprendizagem não precisariam estar conectados a um sistema de controle. Poder-se-ia prever sistemas de apoio através dos quais pudessem ser resgatadas as situações de atendimento como exemplos para desenvolver o retorno da experiência e as trocas dentro de um coletivo de trabalho que infelizmente não é favorecido nas empresas. Ao contrário, as formas de organização do trabalho dificultam ou mesmo impedem as trocas com os colegas e, por vezes, com os supervisores também. Questiona-se a necessidade de construir todo um sistema de controle que, em tese, serviria para garantir a qualidade e ajudar na aprendizagem, mas que, na realidade, é algo escondido, sem que o atendente o saiba. Não seria eventualmente mais adequado um sistema em que fosse possível receber informações, discutir as dificuldades, escutar os colegas, as suas próprias ligações? Entretanto, essa segunda opção não seria coerente com as idéias tayloristas que tanto influenciaram a criação desses sistemas de atendimento. Uma mudança efetiva conduziria a reforçar experiências na quais a monitoração seja percebida como um mecanismo de aperfeiçoamento dos conhecimentos e das habilidades dos operadores. Nesse caso, autores como Holman et al. (2002) sugerem que a monitoração seria associada ao bem-estar dos atendentes.

\section{O tempo, sempre onipresente...}

A atividade de atendimento é fortemente limitada, constrangida pelo tempo.
O atendente não tem autonomia para regular o seu ritmo, o fluxo de chamadas e as pausas. No entanto, a relação com o cliente requer, em princípio, uma certa flexibilidade do tempo para que se possa desenvolver um tratamento adequado, uma verdadeira implicação pessoal na resolução dos problemas. Contudo, como a cobrança com relação aos tempos médios de atendimento é constante, corre-se o risco de que o cumprimento das metas de tempo se torne um fim em si, impedindo que se crie uma relação compatível com as solicitações do cliente. A compressão do tempo serve também para transformar o relacional, ao se pensar nas diferentes dimensões de sua complexidade, em objetal, num processo de reificação, o que é freqüente nas centrais de atendimento. Pode-se considerar como uma forma de violência, de tentativa de enquadramento da variabilidade, em que os resultados tangíveis seriam também corpos comprimidos, manifestando-se por meio das LER/DORT.

Um outro aspecto apontado pelos atendentes é relativo à definição, a priori, da distribuição das pausas, que seria um dos principais fatores de rigidez e inflexibilidade. Na organização estudada por Freire (2002), a supervisão dispõe de um aplicativo para controlar os atendentes e pode controlar a posição de cada um, se estão no atendimento, há quanto tempo, se estão no lanche ou no banheiro etc.

Para os atendentes, beber água para preservar a voz também significa a necessidade de ir ao banheiro com mais freqüência, o que é um problema diante da dificuldade para se afastarem de seus postos de trabalho. A mesma condição é relatada na pesquisa de Galasso et al. (2004). Assim, os ritmos e as pausas são determinados e controlados pela organização, gerando mais insatisfação. Questiona-se se o controle que é definido para o trabalho acaba se tornando também um condicionador do metabolismo dos atendentes, um impedimento para o funcionamento orgânico que compromete de forma significativa a saúde.

\section{Como dar conta de tanta informação e das inadequações das ferramentas?}

A utilização de programas de computador também é um problema significativo para os atendentes. Não raro se encontrou o uso de sistemas com plataformas operacionais distintas e incompatíveis. Na mesma tela, os atendentes precisavam navegar por "janelas" que tinham como base siste- 
mas operacionais diversos, construídos a partir de linguagens diferentes. Esse tipo de problema influencia substancialmente o tempo de atendimento e também acarreta uma "sobrecarga cognitiva" considerável. Mediar uma relação na qual a racionalidade técnica é representada por sistemas operacionais de difícil utilização e compreensão e em que a racionalidade do cliente e a do atendente não são consideradas de maneira adequada nas funcionalidades do sistema informatizado é considerado pelos atendentes como algo muito difícil. A racionalidade do operador deve ser modela$d a$ nesse papel de mediador entre o sistema e o cliente.

São freqüentes os problemas derivados de eventos em que o sistema está lento ou mesmo inoperante. Nessas situações, o atendente precisa agir somente para tentar acalmar o cliente que, muitas vezes, está nervoso devido a uma longa espera na fila. Encontram-se, ainda, situações em que a ligação cai e o cliente é obrigado a ligar novamente, esperar na fila e começar um novo diálogo com um outro atendente. As inoperâncias não são apenas aquelas oriundas dos momentos de pane do sistema informatizado. Em muitas situações, as inoperâncias ocorrem ao longo do processo, seja porque o problema ainda não foi tratado pelas equipes de retaguarda, seja porque as informações que o cliente enviou se perderam ao longo do processo e entre áreas operacionais que pouco se comunicam. Assim, o atendente precisa explicar aquilo que o cliente não deseja ouvir ou, ainda, não pode explicar, restando-lhe tergiversar ou adotar estratégias para tentar se manter surdo às reclamações.

Ao se levar em conta a quantidade de informações sobre produtos e serviços colocados à disposição do cliente, os aplicativos (programas de computador) nem sempre auxiliam o atendente, que com freqüência tem que gerenciar de outras formas. Quando o atendente tem dúvidas com relação à demanda do cliente e não localiza a informação nos aplicativos disponíveis, ele busca ajuda, em primeira instância, junto aos colegas mais próximos, atrapalhando muitas vezes o curso do atendimento destes. Em outras situações, busca auxílio do supervisor ou do gerente, que nem sempre estão disponíveis.

Abrahão e Santos (2004) discutem o caráter eminentemente cognitivo do trabalho nas centrais de atendimento. Elas apontam o desgaste resultante da forma de aprendizagem, da resolução de problemas, do processo de decisões, da exigência de atenção, memória e raciocínio, das solicitações visuais e mentais na busca de informações e, ainda, solicitações relacionadas à imprevisibilidade e ansiedade impostas pelas demandas do cliente. $\mathrm{O}$ atendente, além de tratar as informações, tem que dar conta das atribuições exigidas na interação com os clientes, no manuseio de produtos e equipamentos, no atendimento de cada ligação e na busca de informações necessárias. A atividade dos atendentes é fortemente permeada de exigências de natureza cognitiva.

Mascia e Sznelwar (2000) identificam em seu estudo diferentes condutas prescritas. Há uma quantidade significativa de instruções que fazem parte dos manuais do operador, muitas delas desconhecidas por eles. A mesma condição foi encontrada na pesquisa de Freire (2002), na qual ela mostra a relevância dos diferentes documentos que explicitam as habilidades exigidas dos atendentes e as atitudes a serem adotadas durante o atendimento. Um paradoxo interessante a ser ressaltado nesse caso é que as prescrições relativas ao comportamento são genéricas e devem ser adotadas em quaisquer situações. Já com relação aos procedimentos operacionais, que também interferem no atendimento, há muitos que não são bem conhecidos, causando dificuldades para que os atendentes consigam respeitá-los em tempo real. Será que é possível separar a conduta referente à relação de serviço da conduta relacionada ao procedimento operacional?

\section{E a questão psíquica?}

Além de todas as questões ligadas à ação, às possibilidades e aos impedimentos para que o atendente consiga dar conta das exigências do atendimento em si, é importante relevar o aspecto psíquico dessa atividade. Aliada à frustração de não poder resolver muitos problemas e de não ter um retorno adequado quanto aos resultados de suas ações, há muitas situações de conflito para as quais eles não encontram saída, para as quais não conseguem manter o controle. Muitas vezes, os atendentes acabam sendo agredidos, achincalhados pelos clientes. Como agir nestas situações? Eles não podem desligar a ligação ou revidar, devem viver essas situações de maneira individual, são obrigados a incorporar a agressão. Às vezes são apoiados pela hierarquia, às vezes são humilhados, principalmente quando um supervisor ou gerente 
interfere diretamente no atendimento, contradizendo o que o atendente fez ou, ainda, resolvendo um problema que o atendente sabia como fazê-lo, mas não tinha autonomia para tal. A importância do componente psíquico nas situações de atendimento em que o trabalhador mantém contato com o público e recebe reclamações, legitimas ou não, dos clientes já havia sido assinalada por Wisner (1987).

Algumas práticas desenvolvidas pelos atendentes foram identificadas e podem ser consideradas como práticas de resistência. Há situações em que, para manter um padrão considerado coerente com a sua ética e também na tentativa de manter a sua singularidade, criam estratégias para tentar resolver problemas para os quais não têm alçada, buscam também personalizar a relação com o cliente, quando fazem o acompanhamento de um dossiê.

Todas essas práticas são desenvolvidas em desacordo com os procedimentos. Apesar de não haver espaço para tal, buscam, de maneira coletiva, regular o tempo para que não fiquem muitas chamadas em espera, evitando o aumento de clientes nervosos após o tempo de espera na fila. Entretanto, esse tipo de iniciativa pode aumentar a ansiedade para terminar rapidamente as ligações.

Principalmente nos casos de venda, é necessário usar técnicas de sedução para convencer os clientes de que aquela aquisição lhe será proveitosa. Esse jogo de sedução é também enquadrado em procedimentos e o atendente se vê, geralmente, em situações embaraçosas, pois precisa, ao mesmo tempo, seduzir e não transgredir para atingir suas metas. Entretanto, às vezes, precisa abandonar o prescrito, transgredir. Tudo isso sem ter a menor idéia de quem seja o cliente, sem jamais o ter visto. Isso lhes causa uma série de questionamentos, inclusive de ordem moral. Alguns sentem que são obrigados a mentir.

O modo como o trabalho é organizado influencia diretamente os indivíduos, suas aspirações, motivações e desejos, principalmente quando são determinações exclusivas da instituição, estando os sujeitos afastados da possibilidade de contribuir nas regulamentações de seu trabalho ou até mesmo impossibilitados de opinar (DEJOURS, 1987). A rigidez da organização do trabalho retira a participação dos trabalhadores deste processo, deixando-os limitados às determinações superiores. Sendo assim, não há a possibilidade de buscarem uma adaptação espontânea do trabalho a sua realidade nem de manifestar sua experiência nas situações que fogem ao prescrito.

Este sentimento de insatisfação foi estudado por Dejours (apud WISNER, 1994), que aponta como um dos principais pontos de conflito e por conseqüência fonte de sofrimento psíquico no trabalho as relações, muitas vezes rígidas, entre o trabalhador e a organização. Esta relação pode ser considerada como conflituosa quando contrapõe, de um lado, a expectativa do trabalhador e, do outro, a rigidez sobre o modo de funcionamento e produção da organização. A impossibilidade de transformar ou adaptar as regras elaboradas pela organização do trabalho constitui uma fonte de insatisfação ou de sofrimento a partir do momento que os trabalhadores sentem como esgotados seus recursos para transformação. Em decorrência, a saúde pode ser comprometida e ameaçada (ABRAHÃO, TORRES \& ASSUNÇÃO, 2003).

Identifica-se claramente a contradição entre a vontade de fazer, de resolver os problemas dos clientes e a impossibilidade de fazê-lo, pois eles não têm autonomia sobre os processos de trabalho. O estudo de Vilela e Assunção (2004) encontrou nos seus resultados queixas relativas a sentimentos de cansaço, esgotamento mental e impotência diante da rigidez da organização do trabalho. Esta percepção da margem de ação e uma rotina de trabalho com poucas oportunidades para decidir acarretam nos atendentes um sentimento de inutilidade, de não ser suficientemente responsável. É interessante pontuar que, apesar dos atendentes relatarem irritação e descontentamento com os mecanismos de controle, eles se dizem conscientes da necessidade dos mesmos para o bom andamento dos serviços (TORRES, 2001).

Para Maslach e Leiter (1999), quando os trabalhadores não têm controle sobre a sua atividade de trabalho, eles ficam impedidos de resolver os problemas que detectam e, assim, não conseguem regular sua atividade com os interesses da organização, pois o controle unilateral não é um objetivo razoável nem sequer desejável. O mesmo acontece com os atendentes pelo fato de serem controlados constantemente, diminuindo a possibilidade de gerenciarem as situações adversas, pois não têm autonomia para fazer frente aos imprevistos. Ao dificultar esse controle, o trabalho assume uma forma alienada e mecanizada 
que pode impactar de maneira negativa a saúde do trabalhador na medida em que os

\section{À guisa de conclusão}

Quando se pretende definir o projeto do trabalho em centrais de atendimento, é importante mudar o ponto de vista, é necessário adotar visões diferentes capazes de se contraporem àquelas que buscam definir tarefas como se fossem simples e facilmente controláveis. Nessa perspectiva, os autores propõem que se considere o papel integrador da atividade de trabalho e, a partir dela, desenvolva-se uma leitura da atividade de trabalho na sua complexidade. A atividade de trabalho, como é possível evidenciar por meio da Análise Ergonômica do Trabalho, resulta de um compromisso entre o que a tarefa exige e as condições oferecidas aos trabalhadores (GUÉRIN et al., 2001). Pelas pesquisas realizadas, infelizmente esse compromisso ocorre no modelo de organização vigente sobretudo em detrimento da saúde dos trabalhadores e também, em muitas situações, em detrimento da qualidade do serviço.

Os resultados dos estudos mostram o quanto é importante se distanciar de explicações simplificadoras dos fenômenos ligados ao trabalhar. As atividades em centrais de atendimento não se resumem ao simples gesto, à execução do previsto, ao respeito dos procedimentos. Há uma questão irredutível que é a relação com o outro, com o cliente que atua e modifica as tarefas.

Outra questão importante a ser considerada com relação às atividades de serviço discutidas por Hubault (2003) é a dificuldade de se mensurar a produtividade, como medir a relação insumos/resultados, principalmente porque os serviços são, em grande parte, intangíveis. Para esse autor, a relação de serviço contém uma série de características que são dificilmente valorizáveis por uma produtividade que é medida por meio de indicadores que não consideram esses aspectos.

Como avaliar a utilidade do trabalho se a sua essência é desconhecida?

Um outro aspecto fundamental da situação está relacionado com o controle sobre o trabalhador. O trabalho de atendimento, mesmo que seja mediado por telefone, implica uma relação intersubjetiva. Conforme apontado, há paradoxos significativos nesse tipo de produção. Ao mesmo tempo trabalhadores são apenas objetos do controle organizacional (SATO, 2002). em que se busca, por meio dos paradigmas da simplificação, uma homogeneidade no atendimento, pede-se ao trabalhador que seja envolvente, simpático, carismático, cordato, tudo isso sob pressão de tempo e sob a aura do controle. Como vários trabalhadores afirmam, eles vivem com uma sensação de se tornarem robôs. Como trabalhar esse paradoxo e construir sistemas de produção em que o relacional não seja objetal?

Os trabalhadores sofrem. Muitas vezes, têm que se curvar aos imperativos dos sistemas informatizados e fazer um esforço doloroso para se afastarem do conteúdo do trabalho, criar estratégias de defesa, como a busca de mecanização da relação que, no final das contas, reforça essa idéia de serem programados, de incorporarem um controle que era externo e se torna algo interno, presente constantemente.

Seria esta uma situação em que, por meio de diferentes meios persuasivos, estaria assegurada uma verdadeira dominação simbólica (DEJOURS, 1999). As diferentes formas de controle sobre o fazer, as avaliações constantes e mesmo a ameaça de demissão seriam parte deste universo.

Ao contrário, trata-se de pensar a concepção, o planejamento dos métodos de gestão e a formação sob o ponto de vista da complexidade e o deslocamento desse paradigma clássico para uma abordagem capaz de apreender a articulação entre indivíduos e artefatos, ou seja, compreender como os sujeitos individualmente se posicionam e como compartilham suas atividades no âmbito de um processo distribuído e coletivo.

Questiona-se se as diferentes estratégias desenvolvidas pelos trabalhadores seriam suficientes para que eles reduzissem ou eliminassem o sofrimento relacionado com o seu trabalho ou até mesmo se seria possível elaborar estratégias que permitam avanços significativos no que diz respeito aos resultados do trabalho, trazendo mais satisfação para eles e também para os clientes. Temos dúvidas.

As estratégias encontradas nos parecem mais próximas dos mecanismos de 
defesa psíquica mostrados nos estudos clássicos de psicopatologia do trabalho (DEJOURS, 1987), que seriam mais estratégias de sobrevivência e que resultariam numa redução do nível de consciência e de reflexão sobre o problema. O fato de haver tantas pessoas afastadas por problemas de saúde nessas empresas e uma quantidade significativa de trabalhadores que referiam problemas de saúde os mais diversos, sem estarem afastados do trabalho, poderia ser uma indicação de que as estratégias desenvolvidas, que pareceram mais de cunho individual do que coletivo, não trouxeram resultados muito significativos. Isso não significa que todos os trabalhadores vivam uma situação que os levará inexoravelmente ao adoecimento. Entretanto, os resultados permitem afirmar que os paradigmas sob os quais foram projetados os sistemas de produção e as tarefas não são adequados quando se pensa na promoção da saúde por meio de um trabalho que respeite as propriedades e os limites humanos quanto à fisiologia, mas também que permita o desenvolvimento profissional dos indivíduos e dos coletivos de trabalho.

A busca de novos projetos de produção e do trabalho neste setor que não sejam baseados em paradigmas simplificadores é um dos caminhos possíveis de ser trilhado se a intenção é reduzir as contradições encontradas. Para tanto, sugere-se que sejam adotados outros pontos de vista para projetar esse tipo de trabalho. Por exemplo, a adoção de novos paradigmas nos projetos da produção e do trabalho em centrais de atendimento, como aqueles oriundos da Teoria da Complexidade (MORIN, 1999; MONTEDO \& SZNELWAR, 2004), pode

\section{Referências bibliográficas}

ABRAHÃO, J. I. Restruturação produtiva e variabilidade do trabalho: uma abordagem da ergonomia. Psic.: Teor. e Pesq., v. 16, n. 1, p. 49-54, 2000.

ABRAHÃO, J. I.; SANTOS, V. O. O controle no trabalho: os seus efeitos no bem-estar e na produtividade. In: TAMAYO, A. (org.). Cultura e saúde nas organizações. Porto Alegre: Artmed, 2004. p. 208-226.

ABRAHÃO, J. I.; TORRES, C. C. Entre a organização do trabalho e o sofrimento: o papel de mediação da atividade. Revista Produção, v. 14, n. 3, p. 67-76, 2004. abrir espaço para que os trabalhadores possam viver uma situação profissional mais favorável. Para tanto, é importante adotar a idéia de que o mundo do trabalho é dinâmico, sujeito a muitos tipos de variação, que a realidade não se enquadra no prescrito e que, sobretudo, os atendentes precisam agir com estratégia, dentro de um espectro de ações que lhes permita resolver de fato os problemas existentes com os clientes.

Seria interessante também incorporar nos pressupostos de projeto as propostas de Bruno Maggi (2006). Em seu livro O agir organizacional, o autor defende a perspectiva segundo a qual as organizações são fruto de processos de ações e decisões dos diferentes sujeitos agentes. Para tal, seria importante considerar que deve haver margem discricionária para que se possa desenvolver melhor as atividades desses trabalhadores.

Seria, portanto, preciso encarar o desafio de projetar de maneira diferente os sistemas de atendimento ao cliente em que sejam incorporadas as questões, os pontos de vista e as propostas tratadas neste artigo. Em todo e qualquer projeto do trabalho há uma perspectiva sobre o ser humano, na maioria das vezes, subentendida. Seria importante explicitar e colocar em debate a questão para qual sujeito, para qual ser humano se projetam a organização e o conteúdo das tarefas. Se forem mantidos os paradigmas tradicionais mostrados neste artigo, seriam projetos nos quais o ponto de vista adotado seria aquele em que estariam subentendidas a anulação do sujeito e a construção de um ser humano inexistente: uma máquina?

ABRAHÃO, J. I.; TORRES, C. C.; ASSUNÇÃO, A. A. Penosidade e estratégias de atenuação do risco: o caso das telefonistas de uma instituição pública. Estudos, Vida e Saúde, v. 30, n. 1, p. 85-110, 2003.

ARENDT, H. A condição humana. São Paulo: Edusp, 1981.

CALDERON, J. Limplication quotidienne dans un centre d'appels: les nouvelles initiatives éducatives. Travailler, n. 13, p. 7594, 2005.

CLOT, Y. La fonction psychologique du travail. Paris: PUF, 1999. 
DEJOURS, C. A loucura do trabalho. São Paulo: Cortez/Oboré, 1987.

Violence ou domination. Travailler, n. 3, p. 11-30, 1999.

Novas formas de organização do trabalho e lesões por esforços repetitivos (LER): abordagem através da psicodinâmica do trabalho. In: SZNELWAR, L. I.; ZIDAN, L. N. (orgs.). O trabalho humano com sistemas informatizados no setor de serviços. São Paulo: Plêiade, 2000. p. 37-44.

Le corps, d'abord: corps biologique, corps érotique et sens moral. Paris: Payot, 2001.

L'évaluation du travail à l'épreuve du réel. Paris: INRA, 2003.

A metodologia em psicodinâmica do trabalho. In: LANCMAN, S.; SZNELWAR, L. I. (orgs.). Christophe Dejours: da psicopatologia à psicodinâmica do trabaIho. Brasília/Rio de Janeiro: Paralelo 15/Fiocruz, 2004. p. 105-126.

FOUCAULT, M. Vigiar e punir: nascimento da prisão. Petrópolis: Vozes, 1987.

FREIRE, O. N. Ser atendente a vida toda é humanamente impossível: serviço de teleatendimento e custo humano do trabalho. 2002. 110f. Dissertação (Mestrado em Psicologia), Universidade de Brasília, Brasília, 2002.

GALASSO, L. M. R.; ROCHA, L. E.; GLIMA, D. R. Situação de trabalho em centrais de atendimento telefônico de empresas de transporte aéreo e de saúde em São Paulo. In: CONGRESSO DA ASSOCIAÇÃO NACIONAL DE MEDICINA DO TRABALHO (ANAMT), 12, 2004, Goiânia. Anais..., 2004.

GUÉRIN, F. et al. Compreender o trabalho para transformá-lo: a prática da Ergonomia. São Paulo: Edgard Blücher, 2001.

GUBERT, K. B. Os determinantes da atividade em uma central de atendimento: o caso do disque-saúde. 2001. 119f. Dissertação (Mestrado em Psicologia), Universidade de Brasília, Brasília, 2001.

HOLMAN. D.; CHISSICK, C.; TOTTERDELL, P. The effects of performance monitoring on emotional labor and well-being in call centers. Motiv. emot., v. 26, n. 1, p. 57-81, 2002.

HUBAULT, F. Le travail vaut par la manière dont on en use: contribution de l'ergonomie à la gestion des ressources humaines. In: ALLOUCHE, J. (coord.). Encyclopédie des ressources humaines. Paris: Vuibert, 2003.

MAGGI, B. Do agir organizacional: um ponto de vista sobre o trabalho, o bemestar, a aprendizagem. São Paulo: Edgard Blücher, 2006.

MASCIA F. L.; SZNELWAR, L. I. Contraction du temps, compression du corps. In: CONGRES DE LA SELF, Temps et Travail, 23, 1998, Paris. Actes du... Paris, 1998, p. 289-297.

- Diálogo e constrangimentos do script na atividade de atendimento a clientes. In: SZNELWAR, L. I.; ZIDAN, L. N. (Orgs.). Trabalho humano no setor de serviços. São Paulo: Plêiade, 2000. v. 1, p. 97104.

MASLACH, C.; LEITER, M. P. Trabalho: fonte de prazer ou desgaste? Campinas: Papiros, 1999.

MORIN, E. Ciência com consciência. Rio de Janeiro: Bertrand Brasil, 1999.

MONTEDO, U.; SZNELWAR, L. I. A relação tácita entre a análise ergonômica do trabalho e a teoria da complexidade. In: CONGRESSO BRASILEIRO DE ERGONOMIA, 13, 2004, Fortaleza. Anais... Rio de Janeiro: Abergo, 2004.

SATO, L. Saúde e controle no trabalho: feições de um antigo problema. In: Jacques, M. G.; CODO, W. (orgs.). Saúde mental e trabalho: leituras. Petrópolis: Vozes, 2002. p. 31-49.

SZNELWAR, L. I. Working and impediment: the causes and consequences of inadequate task content and work organization. In: TRIENNAL CONGRESS OF THE INTERNATIONAL ERGONOMICS ASSOCIATION / JOINT CONFERENCE OF ERGONOMICS SOCIETY OF KOREA/JAPAN ERGONOMICS SOCIETY, 15 / 7, 2003, Seoul. Ergonomics in the Digital Age, 2003.

SZNELWAR, L. I.; MASCIA, F. L. The dialogue and the script: the conflict between different logics in costumer services. In: TRIENNIAL CONGRESS OF THE INTERNATIONAL ERGONOMICS ASSOCIATION, 1997, Finland. Proceedings... Tampere, Finland, 1997. p. 463-470.

. The organisation of work based on standardisation: the question of scripts in call centers. In: CONFERENCE ON ORGANIZATIONAL DESIGN AND MANAGEMENT, 6, 1998, Hague. Human Factors in Organizational Design and Managment VI, v. 1, p. 647-652, 1998. 
SZNELWAR L. I.; VEZZÁ, F. M. G.; SOARES, R. F. R. Centralização, fragmentação e intensificação do trabalho numa instituição financeira. In: CONGRESSO BRASILEIRO DE ERGONOMIA, 9, 1999, Salvador. Anais... Rio de Janeiro: Abergo, 1999. v. 1.

TORRES, C. C. A atividade nas centrais de atendimento: outra realidade, as mesmas queixas. 2001. 105p. Dissertação (Mestrado em Psicologia) - Instituto de Psicologia, Universidade de Brasília, Brasília, 2001.

VILELA, L. V. de O.; ASSUNÇÃO, A. A. Os mecanismos de controle da atividade no setor de teleatendimento e as queixas de cansaço e esgotamento dos trabalhadores. Cad. Saúde Pública, v. 20, n. 4, p. 10691078, 2004.
WISNER, A. Por dentro do trabalho: ergonomia, método e técnica. São Paulo: FTD/Oboré, 1987.

A inteligência no trabalho. São Paulo: Fundacentro/Unesp, 1994.

Questions épistémologiques en ergonomie et en analyse du travail. In: DANIELLOU, F. L'Ergonomie en quête de ses principes. Débats epistemologiques. Toulose: Octarès Editions, 1996.

ZIMMERMANN, R. M. M. O paradoxo entre o sentimento de segurança e o controle em uma central de atendimento. 2005. Dissertação (Mestrado em Psicologia) - Instituto de Psicologia, Universidade de Brasília, Brasília, 2005. 